\title{
El seguimiento de Jesús pobre y humilde Cómo bajar de la cruz a los pueblos crucificados *
}

\author{
Jon Sobrino, \\ Centro de Reflexión Teológica. \\ San Salvador, El Salvador.
}

"Desde la perspectiva de los niveles de vida que son normales en Europa occidental podríamos decir que 1,116 millones de personas son pobres de solemnidad, que otros 2,000 millones de personas son pobres, y sólo algo más de la cuarta parte de la humanidad disfruta de niveles de vida que van de decentes a buenos"1. A este hecho clamoroso, el que la inmensa mayoría de la humanidad vive en inhumana e injusta pobreza mientras una minoria acapara y disfruta de los bienes de la tierra, queremos dedicar la reflexión del día de hoy y ver qué dicen los Ejercicios Espirituales de san Ignacio sobre ello. Pero antes quisiera hacer dos observaciones previas.

La primera es que hablar sobre la pobreza es difícil. Desde el tercer mundo el hecho es evidente, y es tan grave que para recuperar toda su crudeza, al menos en el lenguaje, hablamos aquí de "pueblos crucificados"2. En otros mundos, sin embargo, este clamoroso hecho, aunque teóricamente sea conocido, tiende a ser interesadamente ignorado y maliciosamente encubierto. $Y$ esta diferencia en la percepción de la pobreza divide los espíritus y lo hace con mayor fuerza, en mi opinión, que la diferencia en visiones ideológicas, filosóficas y teológicas.

La segunda es que la exigencia de enfrentarse con el pueblo crucificado es

- Ponencia presentada en el II Congreso Intemacional de Ejercicios Espirituales de san Ignacio, Loyola, 20-26 de septiembre, 1991. 
absoluta -con Ejercicios o sin ellos, pudiéramos decir- para todo ser humano y cristiano. Lo exigen las estadísticas que hablan de una pobreza masiva, cruel y en aumento. Lo exige la teología - ciertamente la de la liberación-, que ve en el pueblo crucificado "el" signo de los tiempos, signo, a la vez, de la presencia del Dios escondido, de la exigencia de Dios a bajarlo de la cruz y de la salvación para quienes dedican su vida a ello. Lo exigen los documentos de la Iglesia (ciertamente en América Latina, Medellín y Puebla). Y lo exige la máxima autoridad de la Companía de Jesús: la fe-justicia de la Congregación General XXXII y la opción por los pobres de la Congregación General XXXIII.

Lo.que vamos a reflexionar el día de hoy no es, por lo tanto, si los Ejercicios deben ser puestos en relación con el pueblo crucificado, sino cómo. En este sentido daremos mayor ullimidad -metodológicamente- al pueblo crucificado que a los Ejercicios, aunque con la esperanza fundada de que éstos pueden ayudar mucho a aquél.

Desde esta perspectiva no tendrla sentido objetar que los Ejercicios son sólo un método para encontrar la voluntad de Dios, y que por ello no debe exigírseles de antemano nada concreto, ni siquiera la posible opción por el pueblo crucificado, o recalcar que su tratamiento específico de la pobreza está al servicio de encontrar la dicha voluntad de Dios y en el contexto del seguimiento del Jesús pobre y humilde.

Por lo que toca a lo primero, si los Ejercicios no tuvieran nada que ofrecer a enfrentar cristianamente la realidad del pueblo crucificado irían contra la manifiesta voluntad de Dios hoy, se tomarian hisbricamente irrelevantes y habrían perdido su justificación histórica. El pueblo crucificado, en efecto, configura el mundo de hoy, y lo configura - aunque esto pueda ser objeto de discusión- de manera más primaria incluso que las otras realidades que se analizan en este Congreso: realidades religiosas, personales y eclesiales.

Por lo que toca a lo segundo, sería ingenuidad intentar contemplar al Jesús pobre y humilde sin tener noticia del empobrecimiento y humillación que campean por el mundo, y sería ironía pedir la gracia de ser puestos en la pobreza y humildad del Hijo sin relacionarla con la suerte de la mayor parte de la humanidad que vive empobrecida y humillada, sin pedirlo y por necesidad. Ambas cosas no son lo mismo, por supuesto, pero ampoco se pueden separar sin más.

Segín esto, la finalidad de esta exposición es ante todo tratar de iluminar el problema crucial de la pobreza en el mundo de hoy y preguntarnos seriamente desde el espíritu de san Ignacio qué podemos y debemos hacer para darle solución. Para ello vamos a presentar el aporte de los Ejercicios a transformar la realidad del tercer mundo ante la pregunia que nos hacen los pueblos crucificados - pues por mucho que sean un mélodo están también configurados por contenidos-, pero antes vamos a presentar también el aporte del tercer mundo a 
superar las limitaciones de los Ejercicios y de la espiritualidad ignaciana en general con respecto a la pobreza.

\section{El aporte del tercer mundo a los Ejercicios}

Los Ejercicios son algo creatural y limitado, y no se los puede absolutizar por lo tanto. Esta observación es obvia, pero nunca está de más recordarla, pues la tendencia a absolutizar lo que no es absoluto siempre está presente - y más en celebraciones de aniversarios-, lo cual conlleva también consecuencias negativas.

En general, la absolutización de un texto tiende a convertirlo en sólo un texw, letra sin espíritu, y a generar una escolástica que es la mejor manera de declararlo muerto. $Y$ eso $-y$ menos el triunfalismo que suele acompañar a la absolutización - no hace ningún bien ni a san Ignacio, ni a los Ejercicios, ni a nosotros. Y en este caso sería, además, grave incoherencia con el meollo mismo de la vivencia espiritual de san Ignacio, pues él insiste hasta el escrúpulo en que sólo Dios es Dios, y en que Dios es mayor que rodo lo creado. Si algo no debiera ser absolutizado por lo tanto es, precisamente, un texto ignaciano. (Sin embargo parece que a veces no es así y que se tiene más libertad para hablar y criticar, por ejemplo, la eclesiología de las cartas pastorales que la de san Ignacio.)

Por lo que toca ya en concreto al pueblo crucificado, hay que recordar las limilaciones que puedan tener los Ejercicios por una razón muy específica: como su realidad quiere ser eficazmente encubierta, se pudiera apelar para su encubrimiento a lo que san Ignacio "no dice". Lo peligroso aquí no serian las limitaciones del texto en sí mismo, sino el usar de ellas para no enfrentarse con lo que Dios dice con claridad a través del pueblo crucificado. $Y$ es que la ortodoxia literalista casi siempre acaba en reduccionismo y con frecuencia puede acabar también en alienación.

Por último, hay que preguntarse por qué no nos cambian los Ejercicios ${ }^{3}$, por qué tantos siglos de dar Ejercicios a tantas personas, a tantos alumnos y exalumnos de los jesuitas, a tantos líderes, religiosos, eclesiásticos y jerárquicos, no han servido para descubrir y propiciar lo que es central en el Evangelio: la predicación de la buena nueva a los pobres y oprimidos de este mundo. $Y$ por qué todavía hoy es tan difícil que instituciones llevadas por jesuitas, colegios, universidades..., descubran eso que es central, por qué es tan difícil que los jesuitas acepten sinceramente - al menos en la teoría — la fe-justicia y la opción por los pobres, y por qué es tan fácil, por otra parte, aducir argumentos para no hacerlo, siendo así que otros, sin hacer necesariamente los Ejercicios, con la lectura del Evangelio y la mirada puesta en la realidad, lo descubren y lo ponen por práclica. 
Estas preguntas hay que hacerlas sin anacronismos ni irreales idealismos, por supuesto, pero tampoco se pueden pasar por alto a la ligera. Indudablemente no hay por qué echar la culpa de lo dicho a los Ejercicios, al menos no en lo sustancial, pero debiera ponemos en guardia sobre el cormo se dan los ejercicios y también sobre sus propios condicionamientos y limitaciones. Por ello, junto a sus importantes aportes, es necesario analizar también sus posibles limitaciones históricas y teológicas.

A continuación, vamos a analizar aquellas que más se relacionan con el tema de hoy. Las vamos a exponer en forma de tensión entre lo que san Ignacio dice de positivo y lo que - dada su época- no podfa decir, pero que hoy es necesario y decisivo que sea dicho.

\section{(a) EI Jesús pobre y los pobres reales}

Los Ejercicios tratan el tema de la pobreza para ayudar al ejercilante a hacer una buena elección, y, más específicamente, la tratan en relación con el Jesús pobre y humilde al que hay que seguir. Siguiendo la mejor tradición cristiana, san Ignacio analiza la pobreza como modo del seguimento de Jesús, como la mejor salvaguarda contra la tentación de poder, tentación a la que - muy evangélicamente- es especialmente sensible, y como forma de denuncia profética, aunque implícita, contra la corrupción de la Iglesia de su tiempo, por lo cual exige para sí y para los suyos "predicar en pobreza". En conjunto, pues, san Ignacio enfoca la pobreza más como un bien (una virtud centralmente evangélica) que como un mal (la realidad social de los injustamente empobrecidos).

Cierto es que en su vida real esto no le llevó a olvidar a los pobres reales ni a eludir la exigencia ética de qué hacer con ellos. En la conocida carta a los jesuitas de Padua, san Ignacio relaciona el seguimiento del Jesús pobre con los pobres reales, e incluso teologiza su relación: "Son tan grandes los pobres en la presencia divina que principalmente para ellos fue enviado Jesucristo en la tierra ... La amistad con los pobres nos hace amigos del Rey Eterno"4.

Hay aquí un fundamento importante de lo que hoy se llama "opción por los pobres", pero nos parece que la prioridad recae más sobre el Jesús pobre que sobre los pobres reales. Pudiéramos decir que el análisis de los pobres es cristológico, con toda la riqueza que eso ofrece, pero que no es teologal $(y$, por supuesto, no es económico-social) $)^{3}$. San Ignacio se concentra más en el Cristo pobre al que hay que seguir porque eso nos asemeja al vere homo, que en el aspecto teologal. Según el enfoque teologal, sin embargo, la existencia misma de los pobres reales es, por una parte, la máxima expresión del pecado del mundo y de la negación de la voluntad de Dios, y, por otra, esos pobres reales son sacramentos de Dios quasi ex opere operato y destinatarios privilegiados de su buena noticia, datos que con toda claridad aparecen en el Antiguo Testamento (Exodo, 
Profelas...) y en el Nuevo Testamento (Magnificat, bienaventuranzas de Jesús en Lucas...).

\section{(b) Pobres reales y empobrecidos históricamente}

A esto se aflade la carencia de una visión estructural y dialéctica de la realidad. En el análisis social, san Ignacio no esta a la alura de otros contemporáneos suyos como Bartolomé de Las Casas o santo Tomás Moro, lo cual tiene repercusiones incluso en la comprensión de la pobreza como vinud y como ejercicio del seguimiento de Jesús.

Ya hemos dicho que san Ignacio se ocupa también de pobres reales, pero su pobreza no aparece como producto de la injusticia -en sI misma expresión de gravlsimo pecado- y los pobres no parecen como producto de la opresión de los ricos. Aunque en la meditación de las banderas, como veremos más adelante, aparece con toda claridad la dialéctica entre riqueza y pobreza, no aparece en ella la dialéctica entre ricos y pobres. De analizar esta dialéctica, aquéllos no sólo aparecerían deshumanizados por causa de su riqueza, sino que aparecerían también y centralmente como injustos, deshumanizadores y verdugos, y los pobres aparecerían no sólo en su faclicidad, sino como víctimas de los ricos y activamente privados de su humanidad por ellos. Según esto, asumir la pobreza hoy es al menos tomar partido en favor de los empobrecidos y en contra de los empobrecedores, en cuanto colectividades configuradoras de la realidad.

De ahý también que en los Ejercicios - y en general en el modo de proceder de san Ignacio ${ }^{6}$ están ausentes algunas realidades que genera y exige por su naturaleza la pobreza histórica infligida injustamente, y que son centrales tanto en la Escritura como en la realidad de hoy: la denuncia de la injusticia ante todo, el tomar partido, el pashos profético, el dar voz a quienes han sido privados de ella, tal como esto se entiende en los profetas, en Jesús, y ahora en Medellín, en Monseñor Romero, en los mártires latinoamericanos...

Visto desde hoy, es también llamativo que, a pesar de su anhelo de persecuciones e injurias para compartir el destino de Jesús, no aparece un tipo de persecución específica, esos "oprobios y menosprecios" que no sólo acompañan históricamente al hecho de ser pobres, sino que sobrevienen por necesidad a la lucha por dejar de serlo y a la activa defensa que se hace de ellos. Y no aparece, por último, la posibilidad del martirio por causa de la justicia, por causa del reino de Dios.

Todo est - defensa de los pobres, profecía, persecución y maririo- no son sólo realidades importantes, sino realidades centrales en Jesús y en su seguimiento actual. San Ignacio es insigne en el seguimiento del Jesús pobre y humilde, pero por las condiciones histórico-eclesiales y los conocimientos biblicos de su tiempo no llega a atisbar lo que hay de históricamente empobrecedor en el 
seguimiento de un Jesús profeta que, por ello, llega a ser mártir.

\section{(c) El rey eternal y el reino de Dios}

La meditación del rey eternal propone elementos muy importantes de la estructura del seguimiento: llamada a seguir a Jesús en una misión (conquistar lodo el mundo), exigencia al asemejamiento con su modo de proceder, con padecimientos y triunfos (en trabajos y en la victoria), disponibilidad y generosidad sin límites en la respuesta (la oblación) y la gracia tan anhelada por san Ignacio de ser aceplado en ese modo de vida ("queriéndome vuestra santísima majestad elegir y rescibir en tal vida y estado").

Esta meditación fundamental recalca que la vida cristana, como la de Jesús, es misión. En ella se llana a la persona a "conquistar loda la tierra de infieles... todo el mundo, todo los enemigos...", y - se supone- esa conquista es para transformar el mundo según la voluntad de Dios. Lo que el texto pone de relieve en directo, sin embargo, es la transformación del individuo que ha sido llamado, y no aparece con la misma claridad cuál deba ser la transformación en la sociedad como tal.

Esta concentración en la persona del ejercitante en esta meditación clave pucde provenir de la misma finalidad de los Ejercicios (vencerse a sí mismo y ordenar la propia vida), pero pareciera desconocer, quizás, que incluso para esto último es importante lo que se hace extemamente; en otras palabras, la dialéctica entre transformarse uno mismo y transformar la realidad.

En términos teológicos, falta la noción del reino de Dios tal como lo predicó Jesús y como lo ha ido redescubriendo la exégesis en el último siglo, falta el contenido fundamental de la transformación histórica del mundo y falta el papel central de los pobres, para quienes en direclo es el reino de Dios.

No quiere esto decir que san Ignacio no quisiera cambiar el mundo de su liempo, por supuesto, pero esa transformación no esú pensada en directo como renovación de la totalidad humano-social. Si hay que encontrar en él alguna totalidad que debe ser construida, ésta está pensada más en términos religiososeclesiales que biblico-históricos: un mundo cristiano, que en la situación concreta de aquel tiempo debía realizarse como mundo calólico, en oposición a otros mundos posibles, el protestante y el musulmán. Lo que sería el equivalente a la construcción del "reino de Dios" es visto más desde la propiciación de la fe que desde la propiciación de lo humano. Es posible que en su época eso debiera de ser asi porque la miseria no era en aquellos días un signo de los tiempos tan clamoroso como en los nuestros. Pero para nosotros, sería una falta de perspectiva histórica mantenemos en los niveles del siglo XVI.

Nada de lo anterior significa, por supuesto, que san Ignacio excluyera en su vida personal y en su calidad de fundador de una nueva orden religiosa activi- 
dades con finalidad secular según la voluntad de Dios (lo que entonces se llamarían obras de misericordia corporales...), y que no fuese incluso un innovador en dar autonomía a las mediaciones seculares, en lo cual fue ciertamente renovador y de lo cual da cuenta la historia de la Compañía. Pero sí significa que su visión de lo que hay que hacer con el mundo es cristianizar - "calólicamente"- lo no cristiano, más que humanizar lo inhumano, aunque haciendo aquello, indudablemente, también pretendería hacer esto y probablemente viese aquello como el mejor modo de lograr esto. Pero no aparece en san Ignacio un tipo de pensamiento utópico al estilo de un Joaquín de Fiore, cuya autoridad en el último tramo de la Edad Media era infinitamente mayor de lo que hoy se le concede, o de su contemporáneo Tomás Moro. Y lampoco aparece que en el centro de la utopía deban estar los pobres.

\section{(d) El Dios mayor y el Dios parcial hacia los pobres}

En san Ignacio, por úlumo, es fundamental y es algo muy específicamente suyo recalcar la experiencia personal de Dios y de un Dios como misterio siempre mayor, inmanipulable en sí mismo y con una voluntad absolutamente soberana e indeducible. En esto no sólo no hay limilación alguna, sino recuperación de la mejor tradición biblica y gran aporte a la mystagogía y a la experiencia de Dios. K. Rahner lo comentaba de esta forma: "La verdadera actitud profunda es auténtica y fundamental: Dios es siempre más grande (y si se quiere, también por eso mismo más pequeño) que la cultura, la ciencia, la Iglesia, el Papa y todo lo institucional. No se puede cambiar a Dios por nada de todo eso"n.

Y sobre la comunicación de Dios a la criatura al mismo Rahner pone estas palabras en boca de san Ignacio: "Una cosa sigue en pie: que Dios puede y quiere tratar de modo directo con su criatura; que el ser humano puede realmente experimentar cómo tal cosa sucede; que puede captar el soberano designio de la libertad de Dios sobre su vida, lo cual ya no es algo que pueda calcularse, mediante un oportuno y estructurado raciocinio, como una exigencia de la racionalidad humana (ni filosófica, ni teológica, ni "cxistencialmente"). Esta convicción, tan simple y a la vez tan desorbitada, me parece que constituye (junto con otras cosas a las que más adelante aludiré) el núcleo de lo que vosotros soléis llamar mi espiritualidad'"s.

Estas grandes intuiciones que tanto han ayudado a que la Compañia haya podido universalizar y secularizar sanamente su misión - de forma revolucionaria con respecto a la vida religiosa de su tiempo- pudieran ser, sin embargo mal interpretadas, aun con buena voluntad, en un punto importante.

A nuestro modo de ver, el problema consiste en lo siguiente. Desde Jesús no se puede presentar la realidad de Dios y de su voluntad en su pura formalidad de misterio sin añadir algún contenido que le sea esencial. Jesús, en efecto, captó lo último de la realidad como un Dios-Padre, es decir, como un Padre tan misterio 
que seguia siendo Dios y como un Dios an bueno y cercano que le llamaba Padre. Formalidad y contenido, misterio y bondad, son tan primigenios lo uno como lo otro y están dialécticamente unidos en Jesús. San Ignacio, por supuesto, aceptaria esto cordialmente, y su vida real muestra tanto su total disponibilidad al misterio del Dios mayor como su total confianza en la bondad de Dios.

Esto que parece pura reflexión teórica tiene en mi opinión la siguiente consecuencia práctica: tambiên hoy, al hacer los Ejercicios, hay que determinar un contenido y una voluntad central en Dios, de modo que aunque esa voluntad deba ser concretada para el ejercitante (desde qué estado de vida, por ejemplo, se va a llevar a cabo), lo central de ella no puede ser puesto en cuestión. Y eso central que no puede ser puesto en cuestión es la parcialidad esencial de Dios hacia los pobres y víctimas de este mundo y su voluntad de liberarlos.

Según la revelación, al mismo Dios le compete esencialmente lo que hoy con retraso de siglos - llamamos opción por los pobres, pues a través de esa opción, y no sólo con ocasión de ella, se reveló a sí mismo (Exodo, Profelas). Existe, pues, una correlación transcendental entre Dios y pobres. Y asi lo afirma Puebla en un texto de audacia teológica sin precedentes. Al hablar de los pobres dice lo siguiente: "hechos a imagen y semejanza de Dios para ser sus hijos, esta imagen está ensombrecida y aun escamecida. Por eso Dios toma su defensa y los ama" (n. 1142)'.

En los Ejercicios no aparece esta parcialidad de la realidad de Dios desde la pobreza - aunque la carta a los jesuilas de Padua contiene muchos elementos que hoy pudieran ser leídos en esa línea- con la fuerza con que aparece su misterio. De nuevo, no hay que sorprenderse, pues el conocimiento de la Escritura no daba para eso. Pero sí hay que tenerlo en cuenta para no caer hoy en el peligro de abstracción en que el mismo san Ignacio no hubiera caído pero en el que sí podemos caer nosolros. Dicho en las grálicas palabras de E. Käsemann, "la voluntad de Dios no es ningún misterio, por lo menos en lo que al hermano atañe y al amor se refiere"10. Dicho en el lenguaje del tema que hoy nos atañe, quien socorre a las víctimas ha encontrado a Dios (Mt 25,35s) y quien practica la justicia conoce a Dios (Jer 22, 15s; Os 6, 4-6).

No se puede apelar, pues, al misterio de Dios para no reconocer su esencial parcialidad hacia los pobres, no se puede apelar a la extraordinaria intuición ignaciana sobre el misterio de Dios para no hacer hoy la obvia voluntad de Dios. Y no haya miedo de que asi se empequeñezca el misterio de Dios. El mismo Rahner lo dice en las palabras antes citadas: "Dios es siempre más grande y, si se quiere, también por eso mismo más pequeño". San Ignacio -con la Escriura y la teologia actual del Dios crucificado- habla del empequefiecimiento de Dios, "la divinidad se esconde" (n. 196). Lo que queremos añadir y recalcar es que ese empequeñecimiento no es arbitrario, sino producto de la parcialidad 
primigenia de Dios hacia lo pequento. Dios es, esencialmente, un Dios de los pobres.

Todo lo dicho hasta ahora hay que entenderlo bien. Seria anacronismo pretender encontrar en san Ignacio teologías, exégesis, ciencias sociales de siglos posteriores, pero serfa deshonestidad hacia nosotros $-y$ hacia el mismo san Ignacio, quien tanto insta a la honradez - no hacer notar su ausencia por las consecuencias que eso tiene para el tema de hoy. En otras palabras, serfa pueril criticar hoy a san Ignacio por lo que no pudo decir, pero sería ceguera no ver que lo que no pudo decir entonces, es hoy absolutamente importante que sea dicho.

Para dar solución a este problema lo esencial es, en nuestra opinión, encontrar el lugar en el que el texto de los Ejercicios dé más de sí. Decía I. Ellacuría que fuentes y lugar del conocimiento teológico no son lo mismo, pero que están estrechamente relacionados, "porque de algún modo el lugar es fuente en cuanto que aquél hace que ésta dé de sí esto o lo otro, de modo que, gracias al lugar y en virtud de él, se actualizan y se hacen realmente presentes unos determinados contenidos"'1!

Esto lo puede ilustrar con claridad un importante ejemplo de actualidad, relacionado con nuestro tema. Las dos instrucciones vaticanas sobre la teología de la liberación afirnan que libertad y liberación son esenciales al evangelio ${ }^{12}$. Históricamente, sin embargo, las cosas no han sido asi durante siglos, y si se ha llegado a ver la liberación en su esencialidad evangélica la razón fundamental ha sido el "lugar" en que se ha leído el evangelio -el tercer mundo-, el lugar en que la inocultable opresión exige la liberación.

Esto sirve a fortiori para los Ejercicios y es más que una obvia exigencia hermenéutica ${ }^{13}$. Por lo que toca al tema de los pobres es una exigencia de la misma revelación. Y es que "la cuestión no está en si alguien busca a Dios o no, sino en si lo busca donde él mismo dijo que estaba"14. Para superar lo que hay de limitación en la comprensión ignaciana de los pobres y la pobreza lo más eficaz es estar en el lugar en que Dios dijo que estaba: los pobres de este mundo. Y ar̃adamos que si no se está en él difícilmente se superará la limitación.

\section{El aporte de los Ejercicios}

Da la experiencia que, leídos en el lugar adecuado - la realidad del pueblo crucificado- los Ejercicios pueden historizarse debidamente y pueden convertirse en medio eficaz para la liberación de los pobres ${ }^{13}$, y queremos recalcar que eso es lo que muestra la experiencia. Aquí vamos a proceder analizando desde esa perspectiva algunos textos centrales de los Ejercicios, aunque no los vamos a considerar fundamentalmente en cuanto textos con un mensaje 
concreto, sino en cuanto fungen como "principios", es decir, como realidades que están en el origen de un proceso y se mantienen a lo largo de él, configurándolo y dándole una dirección.

\section{La honradez con lo real y el "principio-misericordia"}

Si en algo insiste san Ignacio es en la honradez con lo real, a lo que hemos llamado el primer paso de toda espiritualidad'6. Esta honradez primigenia consiste en ver la realidad tal cual es y en reaccionar según sean las exigencias que brotan de ella.

Que san Ignacio insiste hasla el escrúpulo en la honradez con uno mismo, para no dejarse engañar, y en la honradez con Dios para hacer su voluntad es cosa sabida. En la meditación de la encarnación, sin embargo, nos propone contemplar otra realidad, la del mundo, y nos pide mirarlo con los ojos de Dios. Nos pide así contemplar "cómo las tres personas divinas miraban toda la planicia o redondez de lodo el mundo llena de hombres" (n. 102) y pide al mismo ejercitante "mirar loda la faz y redondez de la tierra". Pide, por lo tanto, mirar con amplitud y no con pequeñez, mirar "el género humano".

Lo que encuentra ese mirar es una variedad, sí, pero sobre todo una inmensa tragedia. Y san Ignacio hace notar que de ese mirar la tragedia, que teóricamente pudiera llevar al "se arrepentió Yahvé en su corazón de haber creado al hombre sobre la tierra" (Gen 6,6), surge una reacción contraria y primaria: “hagarnos redención" (n. 107), "salvar al género humano" (n. 102).

A esto sigue invilando san Ignacio: a mirar con honradez la realidad de hoy y a reaccionar con misericordia ante su tragedia. Porque esto es central y porque en este primer paso, lógicamente previo a cualquier hacer, actúan poderosamente "los engaños del enemigo" voy a extenderme un poco en la mirada a la realidad de nuestro mundo.

\subsection{La pobreza que da muerte}

Lo primero que se ve al mirar el mundo de hoy es su inmensa pobreza, y sin embargo, ni siquiera es fácil hablar de ella. En nuestro mundo, el concepto que se tiene de pobreza es análogo y muchas veces llega a ser equívoco. De muy distinta manera entienden la pobreza las víctimas que la padecen, los verdugos que la infligen o simplemente quienes ya la han superado en lo fundamental. En lenguaje convencional, la pobreza se entiende de manera muy distinta según se trate del tercer o del primer mundo".

(a) Vista desde el terccr mundo, la pobreza es la realidad más clamorosa. Lo es cualitativamente porque pobreza significa gravisima dificultad de dominar la vida y, por lo tanto, acercamiento a la muerte. La pobreza da muerte lentamente a causa de las estructuras injustas que la producen, y da muerte violentamente a 
quienes, con todo derecho, quieren luchar contra ella (eso es lo que, en síntesis, significan las revoluciones en el tercer mundo, con razón llamadas revoluciones del hambre), a todo lo cual se anaden los horrores de masacres, torturas, desaparecidos, cementerios clandestinos, capturas, es decir, la necesiadad de sembrar terror para que no surja la tentación de luchar contra la pobreza. Y esa pobreza, por ser lo que acerca con mayor radicalidad a la vida y a la muerte, es también la realidad más determinante para configurar el todo de la existencia de los pobres, incluida su vivencia religiosa.

Pero, además, es clamorosa también cuantitativamente porque pobreza e indignidad no son la excepción y la anécdota en nuestro mundo (excepción sería más bien el veinticinco por ciento que vive en abundancia o en relativo bienestar), sino que es realidad masiva y la que atañe a más seres humanos. El dato es conocido: casi tres cuartas partes de la humanidad, casi 4 mil millones de seres humanos, viven en la pobreza.

Esa pobreza va alarmantemente en aumento. Va creciendo el número de pobres y va creciendo el grado crítico de su pobreza. Es simplemente escandaloso que en un mundo tan desarrollado tecnológicamente la pobreza está alcanzando niveles cada vez más críticos hasta el punto de que ahora hay que adjetivarla como pobreza "crítica", pobreza "biológica", es decir, no alcanzar el mínimo de supervivencia biológica, sin pensar ya en poder satisfacer otras necesidades vilales del ser humano: salud, higiene, vivienda, educación. $Y$ esa pobreza crítica es la que también va aumentando por decenas y centenas de millones

$Y$ por último va creciendo el abismo entre ricos y pobres, como lo reconocieron Puebla y Juan Pablo II, y lo muestran las estadísticas más recientes. "El ingreso per cápita promedio de los miembros de la OCDE es cincuenta veces mayor que el promedio de los 1,116 millones de pobres del tercer mundo. Es como si una vida en el Primer Cuadrante (el mundo de riqueza y tranquilidad) equivaliera a cincuenta vidas del que está en el mundo de la extrema pobreza"le.

En el tercer mundo no hay ninguna duda: esta pobreza es el verdadero signo de los tiempos en el sentido histórico-pastoral'", es lo que caracteriza, de forma trágica y espeluznante, nuestra época. Es, por lo tanto, lo que debe ser tenido en cuenta por la Iglesia, la Compañía y los Ejercicios para que su misión no sea anacrónica y vana.

(b) Desde el primer mundo, sin embargo, las cosas no se ven así. Por un lado, como dice Luis de Sebastián, "lo que preocupa de la pobreza actual, que existe junto a una riqueza tan ostentosa, es que ambas se conocen como nunca antes se habian conocido"zo. Pero, por otro, la pobreza del tercer mundo no llega a interesar en el primer mundo que la produce en muy buena parte, sino que en ese mundo es ignorada y encubierla. 
Desde este punto de vista, lo que caracteriza al primer mundo, el signo de los tiempos, no es la realidad de la pobreza en sí, sino la pobreza en cuanto producida para unos y en cuanto encubierta por otros. Así describe J. B. Metz la actitud de desinterés y encubrimiento de Europa frente a la pobreza: "el postmodernismo cotidiano de nuestros corazones apara a una lejania sin rostro al llamado tercer mundo..., (existe) una especie de estrategia cultural de inmunización de Europa..., un nuevo culto a la inocencia...., un intento por apartarse con el pensamiento de los retos globales de la humanidad..."21 (y lo que aquf se dice de Europa puede aplicarse sin escrípulo a todo el primer mundo). Algunos analistas van más lejos $\mathrm{y}$, al constatar que ya ha comenzado el siglo XXI, caracterizan de esta forma este importante acontecimiento: "el norte contra el sur'm.

Dicho en palabras sencillas, los pobres de este mundo, la inmensa mayoría de la humanidad, no interesan prácticamente a nadie en el mundo de los poderosos; tienen más bien en su contra a los poderes militares, económicos, politicos -y ojală no ocurra lo mismo con los poderes religiosos, eclesiales, universitarios, culurales... La pobreza nunca llega a convertirse en la tragedia central y principal hacia la que hay que volcarse para darle solución, sino que en el primer mundo siempre existen otros problemas más importantes y urgentes que resolver: al nivel socio-polfíco, la amenaza nuclear y ecológica, la nueva situación europea con la caída de los países del Este..., al nivel eclesial, la sccularización, el ateísmo, la proliferación de sectas, el descenso de vocaciones, incluso la libertad dentro de la Iglesia y los derechos de los téblogos, cosas muy buenas, muy necesarias y muy urgentes estas últimas, pero que no se comparan con la necesidad de terminar con la tragedia de la pobreza.

En la actual euforia por la caída del comunismo, los pueblos crucilicados son todavía más ignorados. Se anuncia el fin de la historia y se proclama un nuevo orden mundial. Parafraseando a san Lucas, podríamos decir que los evangelistas del nuevo orden parecen afirmar: "cuando todo el mundo llegó a ser capitalista...", mientras crece en lugar de disminuir el número de crucificados. La indiferencia es estremecedora. Y ni el debate teológico sobre religión-secularización ni el debate filosófico sobre modernidad-postmodernidad parecen hacer central el problema del pueblo crucificado.

\subsection{Moverse a misericordia}

Si miramos al mundo que hemos descrito con los ojos con que el mismo Dios mira a su creación - y eso es lo que nos pide san Ignacio- la reacción es obvia: hay que mirarlo con misericordia. Esa misericordia hay que entenderla bien. No es un puro sentimiento, ni pura ayuda puntual ante una tragedia. Es más bien la reacción primaria ante el sufrimiento ajeno interiorizado al cual hay que responder con ultimidad y sin más razones para ello que el hecho mismo del 
sufrimiento, y es aquello que configura en adelante toda la vida y misión de quien es honrado con nuestra realidad.

La misericordia no to es Lodo. Debe ser historizada según sea la víctima que está herida en el camino, y por ello, porque se trata de miles de millones de seres humanos, la misericordia en el mundo en que vivimos tiene que tornarse en justicia. $Y$ a quien no le satisfaga este insustituible término, piense que lo minimo que hay que dar a quien se ama de verdad es lo que se le debe.

No es ahora el momento de analizar la compleja realidad de la misericordia, pero si de elevarla a principio configurador de nuestro ser humano, cristiano y jesuita. Si la tragedia de este mundo no es capaz de mover a conversión, de iluminar la dirección fundamental de nuestro quehacer, de configurar nuestro seguimento de Jesús y nuestra fe en Dios, podemos preguntamos qué lo hará. En el primer mundo, sobre todo, es necesario despertar del "suefio de inhumanidad" en el que está sumido, como en su dia fue necesario despertar del "sueflo dogmático". Es necesario que la razón se tome en razón misericordiosa y solidaria para humanizar la mejor herencia de la razón occidental y superar sus consecuencias deshumanizantes. Es necesario que la teología se conciba a sí misma no sólo como intellectus fidei, sino como intellectus spei, que dé esperanza a las vicumas, y sobre todo como intellectus amoris (misericordiae. iustitiae, liberationis) que guie la praxis de liberación.

Este es, desde el tercer mundo, el mensaje central de la meditación de la encarnación, pero es importante recordar su dinamismo. Hay que estar dispuestos, primero, a ver la verdad de la realidad y a no reprimirla interesadamente, como nos advierte Pablo. $Y$ hay que reaccionar con el movimiento primario de Dios, con misericordia, sin segundas intenciones, por así decirlo, y con total consecuencia: lleve a donde lleve, hay que ejercitar la misericordia. $Y$ hoy, como en uiempo de Jesús, por cierto, lleva a la denuncia, a la persecución y a la cruz.

Este principio-misericordia es difícil, pero es necesario. Es difícil porque siempre está actuante la tendencia de anteponerse uno mismo —umbién la Iglesia y la Compañía- al sufrimiento ajeno. No abundan los que, como monseñor Romero, anteponen la misericordia hacia las víctimas no sólo a su vida personal, sino a la institución eclesial. Pero es necesario por fidelidad a la fe, por supuesto, y por necesidad histórica: las víctimas necesilan urgentemente defensa y apoyo. A esto deben hoy ayudar los Ejercicios.

\section{La conversión y el "principio-praxis"}

En la meditación de los pecados san Ignacio recalca la maldad histórica del pecado cuya culminación consiste en dar muerte al Hijo, y propone cuál debe ser la reacción del perdonado: transido de agradecimiento se pregunta "qué he 
hecho, qué hago y qué voy a hacer por Cristo" (n. 53). Su significado para hoy es muy importante en tres puntos.

(a) Ante todo, la meditación recuerda la afirmación ya conocida, pero con frecuencia pasada por alto, que existe pecado y que pecado es lo que da muerte: pecado es lo que dio muerte al Hijo de Dios y pecado es lo que hoy sigue dando muerte en la historia a los hijos e hijas de Dios. Desde ahí cobra woda su maldad moral la pobreza: es muerte infligida injustamente, es pecado y el summum del pecado. Y cobra loda su seriedad nuestra existencia sobre este mundo: si y de qué forma participamos en la generación de ese pecado. Sean cuales fueren las ideologías, la muerte de los pobres no es fragmento, sino totalidad, no puede ser relativizada ni suavizada por nada, y ante ella a todo ser humano se le dirige la pregunta "qué has hecho de tu hemano".

(b) San Ignacio insiste en cúl debe ser la actitud del pecador y le propone que tenga valor para mirar a Cristo - víctima del pecado- y recalca el verlo como víctima: "viéndole tal, y así colgado en la cruz" (ibid.). E insiste en un hacer, no sólo en el dolor interno y el propósito de enmienda.

Qué haya que hacer hoy en concreto ante el pecado del mundo es cosa que cada cual, personas, Iglesias, congregaciones religiosas, deben discemir; y, en cualquier caso, hay que buscar las mediaciones analíticas para hacerlo con eficacia. San Ignacio, sin embargo, insiste en dos cosas: en que algo - mucho- hay que hacer, y de ahi el principio-praxis, y en que la mirada al crucificado desencadena la creatividad del hacer. "discurrir por lo que se offresciere" (ibid.).

Esta medilación fue esencial para I. Ellacuria y la historizó para el mundo de hoy de la siguiente manera. "Ante ese pueblo crucificado, preguntarse: ¿Qué he hecho yo para crucificarlo?, ¿qué hago para que lo descrucifiquen?, ¿qué debo hacer para que ese pueblo resucite?'?3.

(c) San Ignacio, por último, se hace estas preguntas como un perdonado, y dc ahí brota su agradecimiento y la generosidad de su hacer como respuesta. En cl mundo actual, el pueblo crucificado es la víctima del pecado, pero es también - cosa que suele pasarse por allo- quien realmente puede perdonar. $Y$ lo sorprendente es que está dispuesto a perdonar. De esta forma, la praxis que surge es una praxis agradececida, que supera mejor la posible hybris de toda praxis. Es lo que afima J .I.González Faus: "hacer la revolución como un perdonado".

Este es el mensaje central de la medilación: mirar a la cara a los pueblos crucificados sin pasar de largo ante ellos, preguntamos con absoluta seriedad por nuestra responsabilidad en sus cruces - "por nuestros pecados"-, vivir y desvivimos por bajarlos de la cruz. Y lodo ello, agradecidamente porque esos pueblos no nos cierran futuro, sino que nos acogen y perdonan. 


\section{La lucidez y el "principio-pobreza"}

El pasaje clásico del tratamiento de la pobreza en los ejercicios es la meditación de las dos banderas desde la perspectiva específica de llegar a conocer la verdad ante el engafio: pedir "conoscimiento de los engafios del mal caudillo" por una parte y "conoscimienlo de la vida verdadera que muestra el summo capitán" por otro (n.139). Y para ello, san Ignacio confronta al ejercitante con dos realidades: riqueza y pobreza. Ambas fungen como principios con un dinamismo propio. La riqueza lleva al vano honor del mundo, de ahí a la soberbia y de ahr a lodos los vicios. La pobreza lleva a oprobios y menosprecios, de ahí a la humildad y de ahi a todas las virtudes.

(a) De esta forma - y visto desde hoy-, san Ignacio ofrece lucidez sobre la estructura de la realidad en sí misma. (1) En la materialidad de la riqueza y de la pobreza está inserto un dinamismo, que, aunque no funcione de forma mecánica, sf está objetivamente presente en la misma naturaleza de las cosas: "para que más fácilmente vengan a ...". Riqueza y pobreza son, pues, principios, no sólo realidades regionales. (2) Esos principios son no soblo diferentes, sino que presentan una disyuntiva: o uno u otro. (3) Son además principios duélicos, pobreza "contra" riqueza, oprobios "contra" vano honor del mundo, humildad "contra" soberbia... (4) Llegan a configurar totalidades cuando, a través del camino recorrido, se llega a todos los vicios o a lodas las virtudes.

(b) Aunque estos principios no se puedan aplicar simplistamente a realidades sociales, esta visión de la realidad ilumina mucho nuestro mundo de hoy, los principios por los que se rige y lo que hay que hacer en un mundo que está de hecho antagónicamente dividido. El primer mundo está basado explicitamente sobre el principio-riqueza, que lleva a la opresión, a la prepotencia y a la ceguera sobre sí mismo y sobre lo que produce. El tercer mundo es ante todo el producto del primero y está, objetivamente, en lucha contra él. Llegar a superar la pobreza sólo puede ocurrir liberándose de la riqueza que la ocasiona.

(c) Teológicamentc, ayuda a comprender la estructura teologal de la realidad. Existe la lucha de los dioses, con sus mediaciones y sus mediadores, entre los que hay que elegir. En concrew, existe el Dios de vida, Dios de los pobres, y los ídolos de muerte que producen víclimas. Existen las mediaciones, el reino de Dios y las sociedades inhumanas, el antirreino. Existen los mediadores, Jesús y los servidores de los idolos. Y entre ambos tipos de realidades hay oposición y lucha.

De esta forma se comprende la dimensión de alternativa excluyente que recorre la revelación. Teo-lógicamente, "no se puede servir a Dios y a las riquezas", "hay que adorar al verdadero Dios y aborrecer a los dioses rivales". Cristo-lógicamente, "quien no está conmigo está contra mr". Antropologicamente, "el que quiere salvar su vida la pierde...". Ayuda a recuperar verda- 
des tan centrales como las controversias de Jesús sobre la verdadera realidad de Dios en contra de las falsas divinidades, su predicación de bienaventuranzas y maldiciones. Ayuda a comprender la estructura de la encarnación y la dimensión agonista y duélica de la vida de Jesús: hacerse came historica es optar por lo pobre de la carne, defender a los pobres contra sus opresores y sufrir persecución y muerte de parte de éstos.

(d) Desde la pobreza, por último, y no desde la riqueza, sino contra ella, se adquiere hoy lucidez —escandalosa y paradójicamente- sobre la utopfa. Como el siervo doliente de Yahvé y como Jesús crucificado, los pobres de este mundo son "luz de las gentes" y "sabiduría de Dios". Dicho en témninos históricos, la totalidad de nuestro mundo, la tragedia y sus causas, se ve mejor desde el tercer mundo que desde el primero. Y desde esa realidad más real se concibe mejor la utopía. Dicho en el lenguaje de l. Ellacuría -conscientemente profético y utópico-, la ulopia es la civilización de la pobreza y la civilización del trabajo que hagan posible el mínimo, que es el máximo don de Dios, como decía Mons. Romero: la vida de los pobres. La utopía es la austeridad compartida, que, en cuanto austeridad, haga posible la vida para todos, pues los modelos que ofrecen los parses de abundancia no son universalizables; y, cn cuanto compartida, exprese fraternidad.

El mensaje de esta meditación es escandaloso, pero es también lúcido para comprender la historia y la revelación. Esclarece la dimensión histórica, dialéctica y duélica de los pobres. $Y$, por otra parte, sostiene que desde esa realidad, que en sí misma es negatividad y expresión del pecado, se puede construir la utopia, llegar a "todas las virtudes".

\section{Jesús y el "principio-realidad"}

Misericordia, praxis y lucidez son realidades y actitudes fundamentales que hoy pueden generar los Ejercicios leídos desde el tercer mundo y que, una vez generadas, mucho ayudan a su salvación. Para terminar, mencionemos, aunque sea muy brevemente, lo más cenural de los Ejercicios: la realidad de Jesús y su seguimiento

Visto desde el tercer mundo, el mayor aporte ignaciano es su insistencia en el seguimiento de Jesús. Para animar al ejercitante, san Ignacio no tiene nada mejor que proponerle que la contemplación de la vida de Jesús. Se trata de lo que hoy llamamos el Jesús histórico, el Jesús real, el que pasó haciendo el bien, curando a enfermos y endemoniados. Indudablemente, los conocimientos bíblicos de la época eran limitados, pero la intuición fundamental de san Ignacio sigue teniendo total validez y es insustituible: todo se juega en ser y hacer como aquel Jesús.

Y visto sobre todo desde cl tercer mundo, el seguimiento de Jesús hoy, 
cuando conocemos un poco mejor su "vera historia", es el mejor aporte que podemos hacer como cristianos al pueblo crucificado, como lo confirma la historia. El Jesús que anuncia el reino de Dios a los pobres y denuncia el anuirreino, el Jesús que siente misericordia de la gente, cura enfermedades y les da de comer, que siente ira contra sus opresores y los denuncia y desenmascara, el Jesús que denuncia el pecado de ricos, fariseos, sumos sacerdotes..., y carga con él para erradicarlo, el Jesús fiel hasta el final, perseguido y ajusticiado por los poderosos, pero resucitado por el Padre para que las víctimas tengan esperanza, ese Jesús sigue generando esperanza, lucidez, creatividad, compromiso, misericordia y amor, y los pobres lo saben suyo. San Ignacio no lo presenta exactamente de esta manera, pero su absoluta convicción y hasta obsesión de que lo que hay que hacer es presentar la vera historia de Jesús de Nazaret y seguirlo, es el gran principio que principia buenas realidades para el pueblo crucificado.

Hemos llamado a Jesús el "principio-realidad" y quisiera terminar esta exposición explicando por qué y en qué sentido. En la tradición cristiana el seguimiento de Jesús suele ser presentado en el contexto de la perfección, después de que ya hemos llegado supuestamente a ser humanos. Tal como están las cosas en el mundo, sin embargo, el seguimiento de Jesús es algo más simple, pcro también más hondo: es la forma de llegar a ser simplemente humanos, de poder vivir con un mínimo de dignidad y sin avergonzamos de ser humanos en un mundo inhumano. Seguir a Jesús pobre y humilde, como nos pide san Ignacio, es hoy, ante todo, defender a los pobres, participar en su pobreza y humillación, y, a veces, en su destino. Y de esa forma llegamos a ser seres humanos "reales", no ficticios.

¿Producen hoy los Ejercicios seres humanos asf, seres "reales" en la pavorosa realidad de nuestro mundo, que cargan con ella y cargando con ella se encaminan a Dios?

Es sabido que desde la Congregación General XXXII y su decreto cuarto, 33 jesuilas han sido asesinados, todos ellos en el tercer mundo. Yo he tenido la dicha de vivir y trabajar con seis de ellos. No sé cómo entendían y hacían los Ejercicios, pero sí sé que de ellos - aunque no sólo de ellos- sacaron luz y motivación. En mis hermanos mártires vi actuantes los principios de misericordia, praxis y lucidez que he analizado. En ellos percibí una fe en el misterio de Dios presente en los crucificados. Y desde ellos entendi un poco lo que suele considerarse quizás como la cumbre de los Ejercicios. la tercera manera de humildad.

Con el permiso y la compresión de san Ignacio, quisiera parafrasear para la actualidad desde los mártires el texto ignaciano de esta forma. "Siendo la gloria de Dios que el pobre viva - como decía Mons. Romero-, queriendo anunciar como Jesús la buena nueva a los pobres y defenderlos de sus opresores, quiero y elijo permanecer con los crucificados más que vivir con sus crucificadores, quie- 
ro y elijo ser estimado por vano y loco más que por sabio y prudente por los poderes de este mundo, siendo así aceptado por los sencillos...".

Estos jesuilas y muchos más han seguido a Jesús hasta el final y han permanecido fieles hasta el martirio. De san Ignacio aprendieron que hay que ser fieles así, porque así hicieron con Jesús. Y quizás han añadido al texio ignaciano que así hacen con su cuerpo en la historia. Lo que aprendieron sin ninguna duda es que en el mundo de hoy sólo se puede ser hombres, cristianos y jesuilas bajando a los crucificados de la cruz.

\section{Notas}

1. L. de Sebastián, "La situación del mundo. Datos e interpretaciones", Exodo 9, 1991, p. 9.

2. I. Ellacuría, "El pueblo crucificado, ensayo de soleriología histórica", Revista Latinoamericana de Teología 18, San Salvador 1989, pp. 305-333: J. Sobrino, "Los pueblos crucilicados, actual siervo sufriente de Yahvé". Concilium 232, 1990, pp. 497-508.

3. Véase, Carlos R. Cabarús, "¿Por qué no nos cambian los Ejercicios?", Diakonía 52, Managua 1989, pp. 415ss.

4. Carta a los padres y hermanos de Padua, 7 de agosto de 1547, en Obras completas de S. Ignacio de Loyola, 1952, p. 743. Sobre el terna véase J. I. González Faus, "De la pobreza a los pobres", en Varios, Tradición ignaciana y solidaridad con los pobres, Bilbao-Santander 1990, p. 37-67.

5. La teologí latinoamericana ha analizado las diversas dimensiones del pobre que superan la concepción tradicional de la pobreza como virtud. I. Ellacuría lo ha sisternatizado con rigor: la realidad social del pobre (realidad socio-econónica, dialéctica, ético-política), su realidad teologal (sacramento de Dios y destinatario primario de la salvación), su realidad sotcriológica (otorgan salvación histórica como el siervo), su realidad eclesial (son centro e inspiración de la Iglesia de los pobres). Véase su artículo "Pobres", en C. Floristán-J. J. Tamayo (eds.), Conceptos fundamentales de pastoral, Madrid 1983, pp. 786-B02.

6. Es conocido que san Ignacio quiso ser un refornador de la Iglesia desde dentro más que un profeta desde fuera, lo cual históricamente pudiera haberle ocasionado o salirse de ella como Lutero o que lo condenaran como a Savonarola. Sus experiencias personales antes de ser lundador de la Compañía (acusaciones de iluminismo, persecuciones, cárceles) le llevaron quizás a la conclusión de que para ser eficaz en la reforma la contestación y la denuncia profética no eran lo más conveniente.

7. "Los jesuitas y el futuro", en Anuario de la Compañta de Jesús 1974-1975, Roma 1975, p. 32.

8. Palabras de lgnacio de Loyola a un jesuita de hoy, Santander 1979, p. $6 s$.

9. La frase anterior es todavía más clara, aunque el contexto es cristológicoeclesiológico: "Por esta sola razón, los pobres merecen una atención preferencial, cualquiera que sea la situación moral o personal en que se encuentren".

10. La llamada de la liberrad, Salamanca 1974, p. 35.

11. Conversión de la Iglesia al reino de Dios, San Salvador 1985, p. 168. 
12. "El Evangelio de Jesucristo es un mensaje de libertad y una fuerza de liberación". Instrucción sobre algunos aspectos de la "seologia de la liberación", Insroducción, 1984; "El Evangelio... es, por su misma naturaleza, mensaje de libertad y de liberación", Libertad cristiana y liberación, Introducción 1, 1986.

13. Personalmente no acabo de entender por qué a la dimensión histórica de la hermenéutica, necesidad de principios de comprensión de textos del pasado, no va unida su dimensión geográfjca, necesidad de principios de comprensión de la realidad de otras partes del mundo.

14. P. Miranda, Marx y la Biblia, Salananca 1972, p. 82.

15. Véase el escrito de I. Ellacuría, "Lectura latinoamericana de los Ejercicios Espirituales de San Ignacio". escrito originalmente en 1974 y publicado ahora en Revista Latinoamericana de Teologia 23, 1991, pp. 111-147.

16. Liberación con espíritu, Santander 1985, pp. $24 s s$.

17. "Después de la caída del este europeo se habla simplemente del sur y del norte.

18. L. de Sebastián, op. cir. 9.

19. Sobre la distinción entre signo de los tiempos en sentido histórico-pastoral y en sentido histórico-leologal, véase nuestro arúculo "Los 'signos de los tiempos' en la teologia de la liberación" en Varios, Fides quae per carisatem operasur. Bilbao 1989. pp. 249-269.

20. Ibid. 9.

21. "Con los ojos de un teólogo europeo", Concilium 232, 1990, p. 491.

22. X. Gorostiaga, "Ya comenzó el siglo XXI: El norte contra el sur", Envio 116, Managua 1991, pp. 34-49.

23. "Las Iglesias latinoamericanas interpelan a la Iglesia espeñola Sal Terrae 3. 1982, pp. 219-230. 